\title{
Sensitivity of present and future surface temperatures to precipitation characteristics
}

\author{
Barry H. Lynn ${ }^{1,2}$, Leonard Druyan ${ }^{1,2, *}$, Christian Hogrefe ${ }^{3}$, Jimy Dudhia ${ }^{4}$, \\ Cynthia Rosenzweig ${ }^{2}$, Richard Goldberg ${ }^{1,2}$, David Rind ${ }^{2}$, Richard Healy ${ }^{1,5}$, \\ Joyce Rosenthal $^{6}$, Patrick Kinney ${ }^{7}$
}

${ }^{1}$ Center for Climate Systems Research, Earth Institute at Columbia University, Armstrong Hall, 2880 Broaday, New York 10025, USA

${ }^{2}$ NASA/Goddard Institute for Space Studies, New York, New York 10025, USA

${ }^{3}$ New York State Department of Environmental Conservation, Albany, New York 12203, USA

${ }^{4}$ National Center for Atmospheric Research, Boulder, Colorado 80306, USA

${ }^{5}$ Woods Hole Oceanographic Institution, Woods Hole, Massachusetts 02543, USA

${ }^{6}$ Columbia University School of Architecture, Planning and Preservation, New York, New York 10027, USA

${ }^{7}$ Columbia University School of Public Health, New York, New York 10032, USA

\begin{abstract}
A model simulation study shows that different diurnal cycles of precipitation are consistent with radically different present and future climate characteristics. In projected future climate scenarios, divergence in the time of day and type of precipitation had very divergent impacts on the radiation balance and consequently on surface temperatures. The relationship between the diurnal cycle of precipitation versus the present and future climate was examined using the GISS-MM5 (Goddard Institute for Space Studies Mesoscale Model 5) regional climate modeling system with 2 alternative moist convection schemes. June-August (JJA) mean surface temperatures of the 1990s, 2050s, and 2080s were simulated over the eastern US on a double nested 108/36 km domain, with the $36 \mathrm{~km}$ domain centered over the eastern US. In the 1990s, one model version simulated maxima in (convective) precipitation during the early morning, while the second model simulated the hour of precipitation maxima with considerable spatial variability (in better agreement with observations). In the futuristic climate scenarios, differences in the time of day of precipitation had very important impacts on the radiation balance at the surface. One version gave more precipitation at night and fewer clouds during the day, promoting higher surface temperatures. The alternative version created more precipitation during the day, consistent with diminished absorption of solar radiation at the surface and consequently lower surface temperatures. The results demonstrate the importance of improving cumulus parameterizations in regional mesoscale and global climate models and suggest that such improvements would lead to greater confidence in model projections of climate change.
\end{abstract}

KEY WORDS: Climate change $\cdot$ Surface temperatures $\cdot$ Model assessment

\section{INTRODUCTION}

Regional mesoscale models have been used to downscale weather and climate analyses by driving them with observational data as lateral boundary conditions. Regional mesoscale models have also been used to generate seasonal forecasts and climate change projections using General Circulation Model (GCM) climate projections as the lateral boundary conditions. For ex- ample, Bates et al. (1993) used a mesoscale model forced with ECMWF (European Centre for Mediumrange Weather Forecasts) observational analyses in order to simulate more realistically the distribution of lake-effect precipitation over the Great Lakes Basin. Giorgi et al. (1993) showed that a nested mesoscale model reproduces observed precipitation patterns better than the driving NCAR Community Climate Model (CCM), and they obtained precipitation projec- 
tions that differed in magnitude, sign, spatial, and seasonal detail from the CCM.

Walsh \& McGregor (1995) obtained improved seasonal climatologies with a regional model over Australia in comparison to GCM seasonal predictions. Likewise, Nobre et al. (2001) obtained improved seasonal precipitation forecasts using the Climate Prediction Center dynamical forecast system over Nordeste Brazil. Liang et al. (2001) developed a regional climate model for US Midwest applications using MM5. They used NCEPNCAR and ECMWF reanalysis to force their model, successfully simulating temporal and spatial variations in a major flood area.

Lynn et al. (unpubl.) describe the 'GISS-MM5' - the mesoscale model MM5 nested one-way to the Goddard Institute for Space Studies General Circulation Model (GISS-GCM). They showed that the choices of boundary layer model, cumulus parameterization, and radiation scheme can have an important effect on the mean summertime simulated temperatures and precipitation, considerations that can affect air quality and heat stress, and hence mortality. The most important factor that affected surface temperature in their simulations, though, was the choice of cumulus parameterization.

Trenberth et al. (2003) identified the simulation of the diurnal cycle as one of the most difficult, yet important aspects of model simulation. The cumulus parameterization determines both how much precipitation falls for a given forcing and when it falls. For example, immediately east of the Rocky Mountains, there is a late night maximum in the diurnal cycle. In the eastern US, especially the southeast, the maximum in the diurnal cycle occurs in the late afternoon. Trenberth et al. (2003) note that east of the

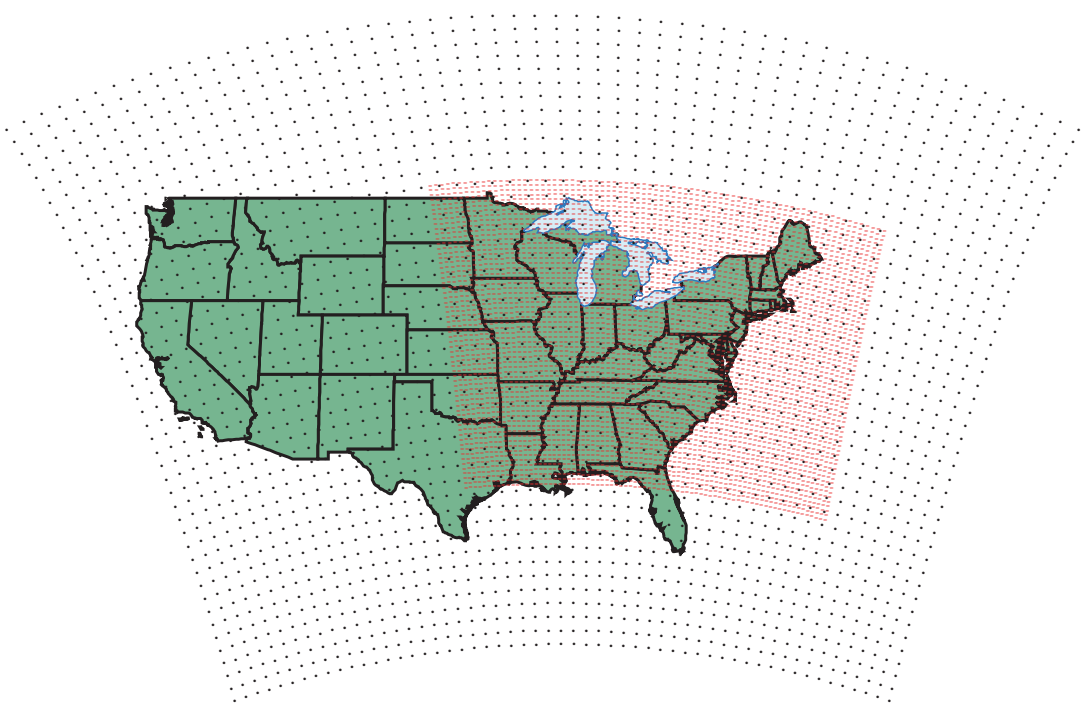

Fig. 1. Outer computational domain (108 km grid spacing: green) and inner domain (36 km grid spacing: red) for MM5 nested simulations
Rockies and the adjacent plains the 'diurnal cycle of lowlevel large-scale convergence is consistent with suppression of daytime convection and favoring of nighttime moist convection.' The nocturnal maximum east of the Rockies is enhanced by late afternoon generation of thunderstorms over the Rockies. In contrast, over the southeast, the 'static instability and surface convergence favor afternoon moist convection in summer.'

\section{EXPERIMENTS WITH THE GISS-GCM AND THE MM5}

In this study, we used the GISS-MM5 in a 108/36 km simulation domain (Fig. 1) to show how the simulation of the diurnal cycle of precipitation can affect regional climate and climate change results. The timing and partitioning of precipitation between convective and non-convective precipitation is shown to strongly affect the surface radiation balance and hence surface temperatures.

The Betts-Miller cumulus parameterization (BMCP) used in the MM5 relaxes (adjusts) temperature and moisture profiles to a reference lapse rate (Betts 1986, Betts \& Miller 1986, 1993, Janjic 1994). Conditional instability is released by the relaxation of the entire profile, rather than by testing individual layers. The scheme used in the present study has no explicit downdraft, although other operational versions do contain explicit downdrafts (A. K. Betts pers. comm.). There are separate reference profiles for deep convection, which precipitates, and for shallow convection, which does not precipitate. The BMCP does not contain explicit triggers for convection, which it initiates for unstable temperature and moisture profiles. Rather, the scheme determines cloud base and cloud top by lifting the first layer, and subsequent layers if necessary, from the ground surface and up. The top layer of the cloud occurs when the temperature of a partially mixed parcel is found to be negatively buoyant. If the top of the parcel extends to levels shallower than $700 \mathrm{mb}$, then the shallow convection scheme is used to adjust the temperature and moisture profiles. If the cloud top is deeper than $700 \mathrm{mb}$ and the convective adjustment produces precipitation greater than zero, then the deep convection scheme is used to adjust the profiles. If the deep convective adjustment does not indicate any precipitation, the BMCP reverts to using the shallow convection scheme and puts the cloud top at $700 \mathrm{mb}$. 
The Grell cumulus parameterization (GRCP) used in MM5 employs a stability equilibrium closure (Grell 1993, Grell et al. 1994), whereby the destabilization by effects other than convective clouds (e.g. large-scale advection) is balanced by the stabilization of the temperature and moisture profile from convective clouds. GRCP uses an exact equilibrium. The scheme parameterizes moist downdrafts, which Grell et al. (1991) showed are crucial to correctly predicting the feedbacks of convection on lower tropospheric temperatures in the mid-latitude environment.

The simulations described below used a modified GRCP that incorporates the effects of radiative and boundary layer forcings (tendencies) in the terms that originally described destabilization from large-scale influences. Hence, the development and the impact of convection on temperature and moisture profiles in this scheme is sensitive to both advection as well as to more localized effects associated with boundary layer and radiative processes. These modifications are used in other versions of the GRCP as well (G. Grell pers. comm.).

GRCP is a relatively simplistic scheme, that only allows for one non-entraining updraft and downdraft. In order for the scheme to be activated, it is also necessary that a model cloud can be created. A model cloud is a single non-entraining updraft/downdraft couplet, which will usually not form if the capping inversion is too thick. In its implementation in MM5, the cloud base is simply the level with the highest moist static energy content, and the cloud top is the level where a nonentraining parcel would become negatively buoyant. The scheme accounts for feedback from compensating subsidence as well as detrainment of updraft and downdraft air. GCRP does not directly depend upon the amount of available buoyant energy. However, Convective Available Potential Energy (CAPE) in midlatitudes sometimes becomes available rapidly because of the existence and removal of strong capping inversions. In this case, the rate of destabilization favoring convection in GRCP can become very large, leading to convection in environmental conditions similar to those that trigger convection in the Kain Fritsch scheme (below).

As noted, the impact of convection on temperature and moisture profiles in GRCP is related to the rate of destabilization of the environment and the strength of the capping inversion, since this affects the formation of the model cloud. In contrast with BMCP, GRCP tests a model cloud for instability, rather than assuming an integrated spectrum of updrafts and downdrafts that evolve towards an end state using a lagged adjustment. Accordingly, GRCP develops deep clouds somewhat less easily than BMCP, which always relaxes the vertical structure of temperature and moisture to predetermined profiles.
The Kain-Fritsch scheme (KFCP; Kain \& Fritsch 1993) assigns a temperature perturbation to a potential cloud parcel based on the grid-scale vertical velocity. It then tests $100 \mathrm{mb}$ layers of atmosphere, beginning with the lowest layer, to determine whether the cloud parcels with their respective temperature perturbations would be buoyant. This procedure is repeated up to the 700 to $600 \mathrm{mb}$ layer. The use of a triggering function in this scheme allows CAPE to build before triggering, but subsequently releases CAPE even when the sounding itself is only conditionally unstable. If the parcel is able to reach its level of free convection, then the impact of convection on temperature and moisture profiles is proportional to the potential buoyant energy, forcing this energy to be removed by the end of the convective period, (30 min to $1 \mathrm{~h}$ ).

The differences between GRCP and KFCP are 2-fold. KFCP depends on a temperature perturbation proportional to the grid-scale vertical velocity and the CAPE itself, rather than the rate of change of destabilization due to advection (and in our modified Grell scheme, radiative and boundary layer forcing). Secondly, GRCP 'decides' whether or not to be activated every time-step, while KFCP remains activated until the complete removal of the potential buoyant energy. Hence, once activated, KFCP may lead to longer lasting clouds and more moist convection than GRCP.

To address this issue, the simulation for JJA 1993 was repeated with the Kain-Fritch scheme, which, like the modified Grell used here, also has a triggering function that is clearly sensitive to the daytime boundary layer forcing. Results (not shown) feature a spatial distribution of the timing of peak rainfall that resembles the modified Grell shown in Fig. 7. Yet, at least for 1993, the simulated surface temperatures (not shown) were considerably warmer than those with the modified Grell. This is due to a greater partitioning of convective versus non-convective precipitation, which allows for more surface solar heating, a result that might be explained by allowing convection to proceed for a predetermined time (as noted above).

Lynn et al. (unpubl.) examined simulation results using the $108 \mathrm{~km}$ grid resolution over the United States. They obtained the most realistic results with a model configuration that included: (1) the boundary layer model from the Medium Range Forecast Model (MRF); (2) the Grell cumulus parameterization; and (3) the Rapid Radiative Transfer model (RRTM). (This combination is referred to hereafter as MIGR, where the 'I' stands for vertical mixing in clouds, or just 'Grell'). Alternative model configurations used the ETA boundary layer model or the BMCP. Yet, the use of the Betts-Miller scheme with MRF and RRTM (hereafter, MIBR, or just 'Betts-Miller') also gave very good temperature results and a more realistic simulation of 
shortwave radiation than Grell, even though precipitation amounts were too large. The contrasting influence of these 2 cumulus convection schemes in simulating regional climate change is the subject of this paper. Note that that both MRF and RRTM are used in both model configurations.

As in Lynn et al. (unpubl.), lateral boundary forcing for the MM5 (Dudhia 1993, Grell et al. 1994) was taken from synchronous simulations using the GISS-GCM (Model III), the coupled atmosphere-ocean version with a horizontal grid spacing of $4^{\circ} \times 5^{\circ}$. In this model, computations are made for 9 vertical atmospheric layers and 13 vertical ocean layers with realistic bathymetry (Russell et al. 2003). The model was run with the climate change scenario referred to as ' $\mathrm{A} 2$ ' (Rind et al. unpubl.). MM5 simulations were initialized with data from a multi decadal simulation of the GISSGCM. Furthermore, the outer nested MM5 was driven by 4 times daily synchronous data interpolated in time and space from GISS GCM simulations to the lateral boundaries of the $108 \mathrm{~km}$ grid domain.

The time-step for each simulation was $270 \mathrm{~s}$, and each simulation was run from May 1 to Sept 1, although May results were discarded. The land surface model used has interactive soil and vegetation (Chen \& Dudhia 2001a,b) - hence precipitation affects the soil moisture and through it the surface energy balance during the course of the model simulation. The concentration of $\mathrm{CO}_{2}$ assumed for the GISS-GCM simulation in each summer was also prescribed for the parallel GISS-MM5 simulations.

Evaluation of both the modeled mean state and the modeled interannual variability of the climate are appropriate measures of model performance (Anthes et al. 1989, Hogrefe et al. 2001, Kunkel et al. 2002). Methods for assessing a model's ability to reproduce the observed variability include the comparison of observed and predicted cumulative distribution functions, the construction of average diurnal cycles, the comparison of the frequency and persistence of observed and predicted extreme values, and the comparison of the variance in different spectral bands of the observed and predicted time series. In this paper, we focus on the comparison of observed and predicted mean fields for three $5 \mathrm{yr}$ periods, in the 1990s, 2050s and 2080s, but include diurnal cycles as well. Several of the other techniques listed above are used in companion papers (e.g. Hogrefe et al. 2004).

For the purpose of model validation, hourly surface station observations of meteorological variables were retrieved from the Data Support Section at the National Center for Atmospheric Research (NCARDSS). Modeled mean JJA horizontal temperature and precipitation distributions for the continental U.S. (25.2 to $49.1^{\circ} \mathrm{N}, 124.5$ to $67.0^{\circ} \mathrm{W}$ ) for $1993-1997$ were compared to JJA 1990-2000 observations of New et al. (2000) gridded at $0.5^{\circ}$ spacing.

The land surface model and the planetary boundary layer model in MM5 in large measure determine the modeled surface skin temperature and the temperature at the first model layer, which here was located at $35 \mathrm{~m}$. The model calculates the $2 \mathrm{~m}$ temperatures from similarity relationships that use the skin (radiometric) temperatures (see Chen \& Dudhia 2001a,b). Model precipitation is a result of the convective and nonconvective (explicit) precipitation schemes.

\section{SURFACE TEMPERATURES AND PRECIPITATION RATES FOR THE 1990s}

Fig. 2 shows 1993-1997 mean temperatures from the GISS-MM5 alternatives, MIBR and MIGR (Betts-Miller and Grell, respectively) and corresponding observed fields, as well as differences between the model results and observations. The Betts-Miller mean temperatures were generally too warm, especially in the southern states. With the exception of the deep south, the Grell temperatures were generally too cool, although they were closer to observations than the Betts-Miller temperatures (see Table 1).

Fig. 3 shows the differences between the maximum, average, and minimum temperatures obtained with Betts-Miller and Grell. The Betts-Miller temperatures were substantially higher than those obtained with Grell, with the largest differences obtained during the day (in the maximum temperatures). Moreover, these differences were largest over the southern states. Fig. 4 shows that the differences in the temperature results were matched by same-sign differences in surface incident solar radiation and in downward longwave flux. Excess solar flux can be attributed to less daytime cloudiness concomitant with the use of BettsMiller, while increases in downward longwave energy are a direct result of higher atmospheric temperatures. The longwave influences are therefore part of a positive feedback cycle promoting higher surface temperatures. Some of the temperature differences were undoubtedly a consequence of contrasting advection

Table 1. Domain-wide observed and simulated temperatures $\left({ }^{\circ} \mathrm{C}\right)$ for the Betts-Miller (MIBR) and Grell (MIGR) schemes (including modified [Mod] and original [Orig])

\begin{tabular}{|lccc|}
\hline Data set & $1990 \mathrm{~s}$ & $2050 \mathrm{~s}$ & $2080 \mathrm{~s}$ \\
\hline Observed & 22.75 & & \\
MIBR MM5 & 24.09 & 26.58 & 29.95 \\
MIGR Mod & 22.42 & 24.39 & 26.23 \\
MIGR Orig & 22.22 & 24.28 & 26.52 \\
\hline
\end{tabular}



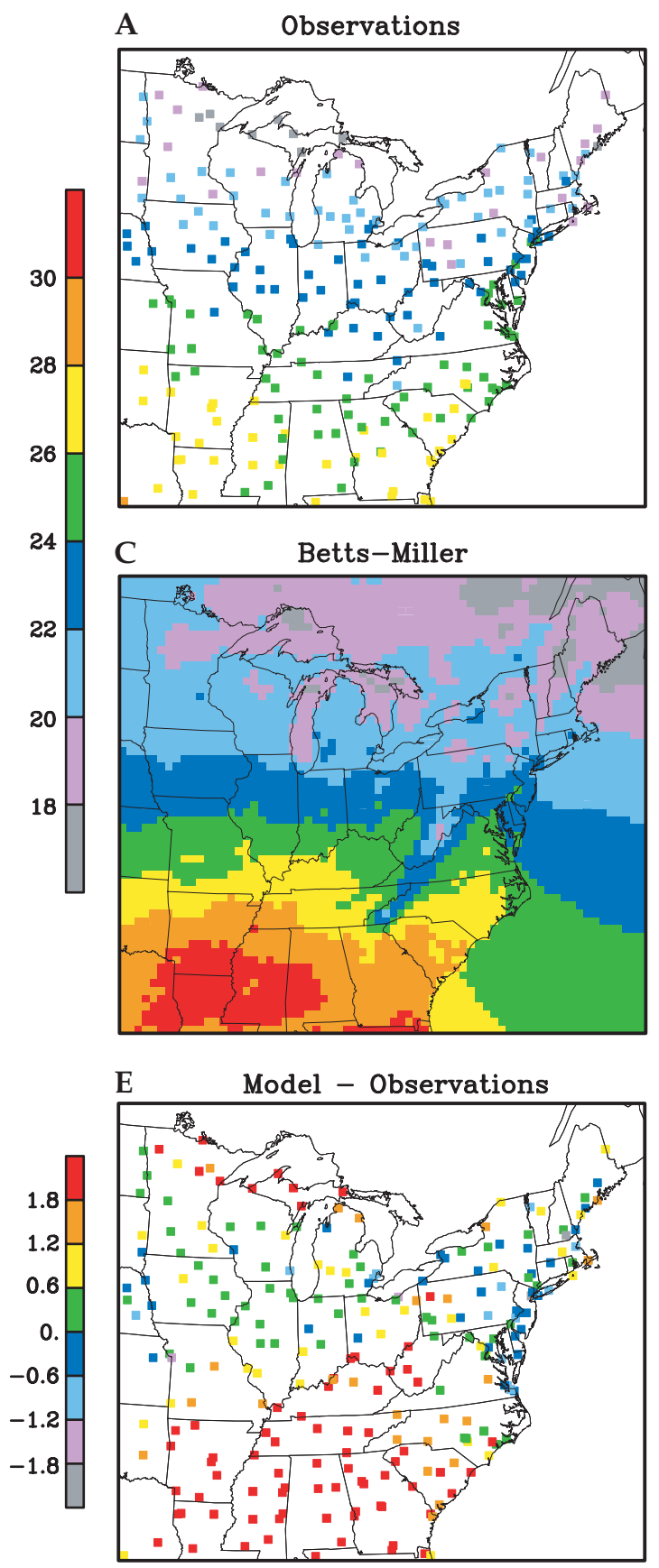

B

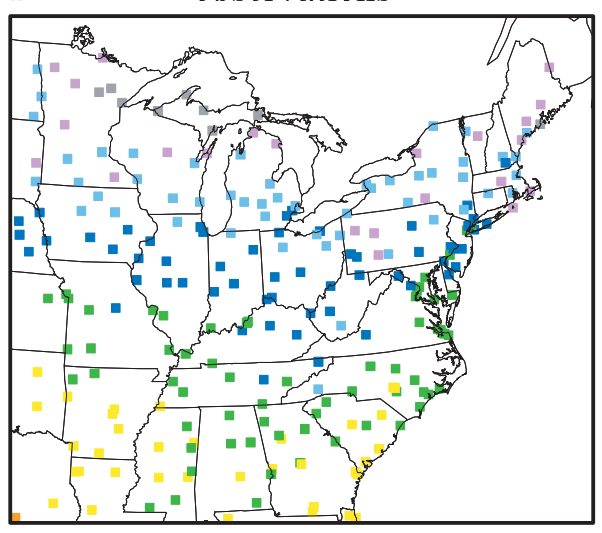

D

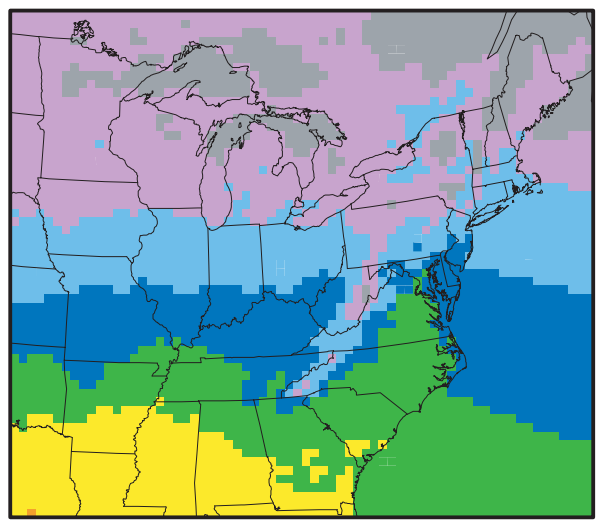

F Model - Observations

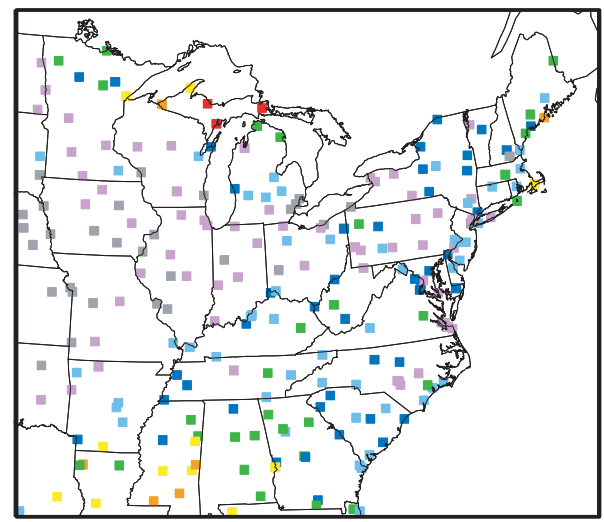

Fig. 2. Surface temperatures $\left({ }^{\circ} \mathrm{C}\right)$ for JJA 1993-1997. (A,B) Station observations; (C,D) MM5 simulated with 2 alternative moist convection schemes; $(\mathrm{E}, \mathrm{F})$ Model minus observations, interpolated to station locations

patterns, but it is noteworthy that the spatial pattern of the minimum temperature differences (Fig. 3B) somewhat resembles that of the longwave differences (Fig. 4B), implying that excess downward energy fluxes at night caused higher temperature minimums.

Fig. 5 shows the mean precipitation distributions obtained with the alternative schemes. Results from the Betts-Miller were generally too wet in the middle western states and parts of the Southeast. Both the modified Grell scheme and the original Grell scheme were drier than the Betts-Miller. There was no obvious relationship between the spatial distribution of errors in the mean precipitation and the mean surface temperature. Nor was there a recognizable spatial correlation between relative precipitation amounts and relative surface temperatures for the 3 alternative model configurations.

For comparison, Fig. 6 shows the spatial distribution of the peak rainfall in the diurnal cycle from observations (Dai et al. 1999, Trenberth et al. 2003). As described above, the peak time of precipitation varied from west to east, with advective processes playing a 


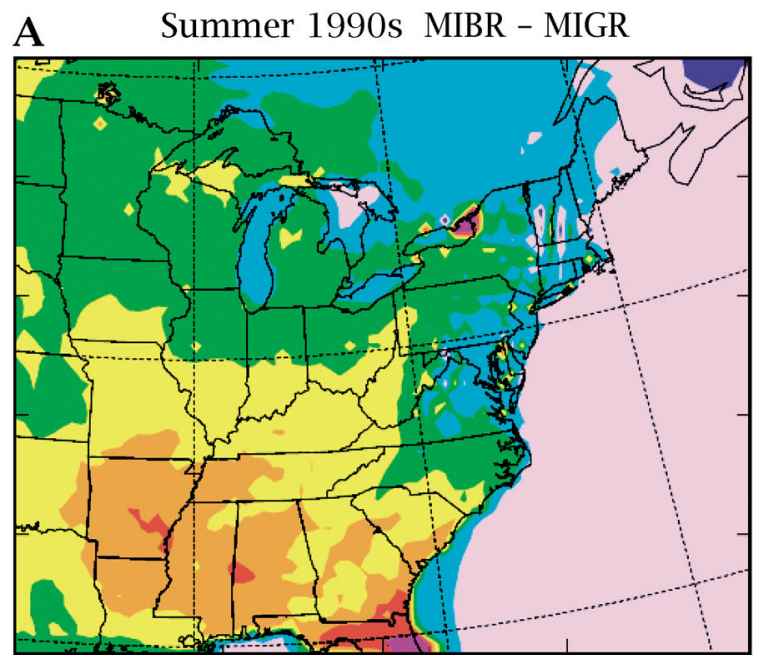

Maximum Temperatures $\left({ }^{\circ} \mathrm{C}\right)$

\section{B}

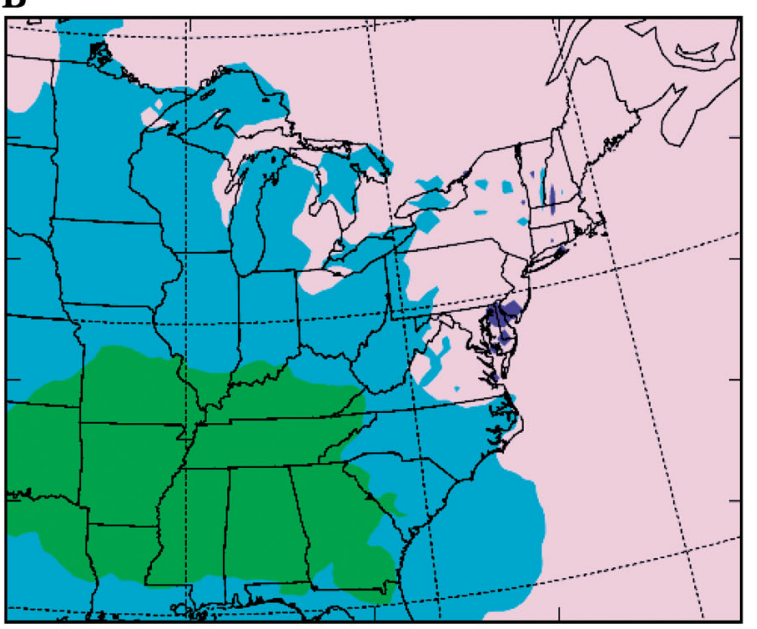

Minimum Temperatures $\left({ }^{\circ} \mathrm{C}\right)$

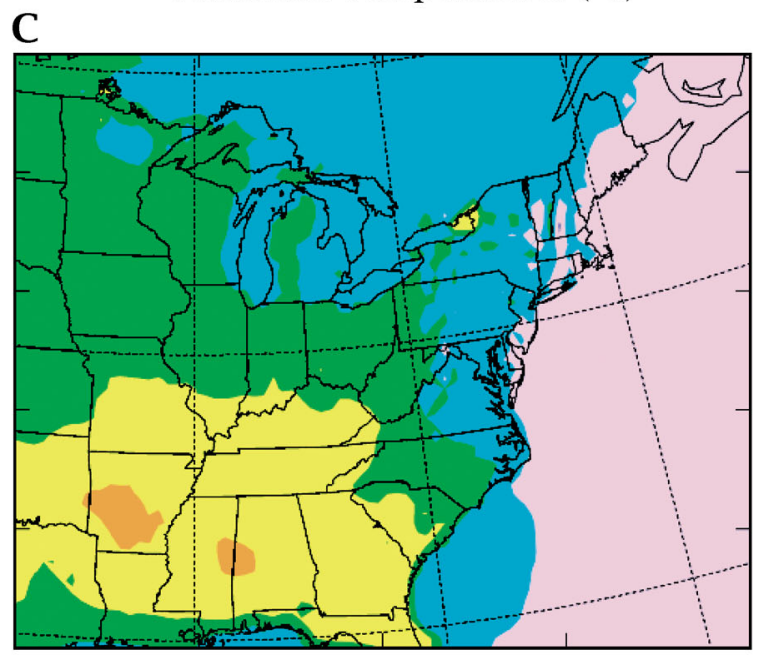

Average Temperatures $\left({ }^{\circ} \mathrm{C}\right)$

Fig. 3. Differences in simulated surface temperatures, MIBR minus MIGR, for JJA 1993-1997: (A) maximum temperatures; (B) minimum temperatures; $(\mathrm{C})$ mean temperatures

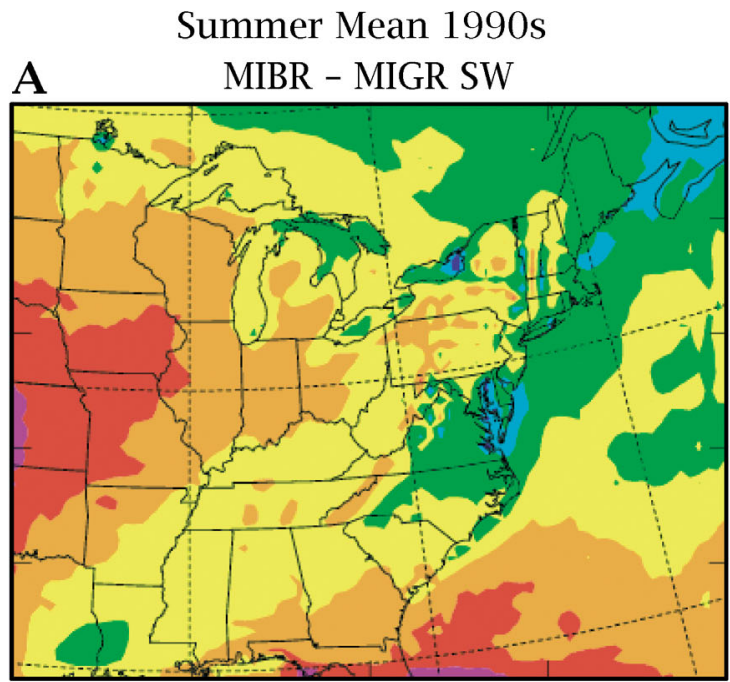

B MIBR - MIGR LW

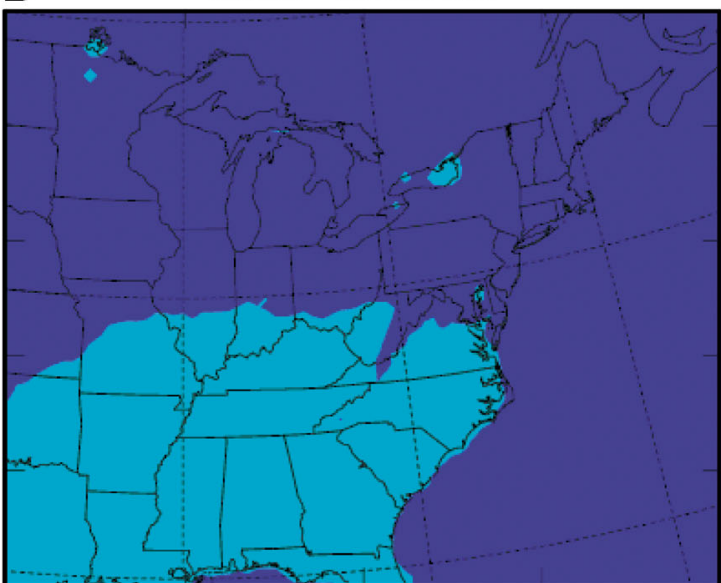

C
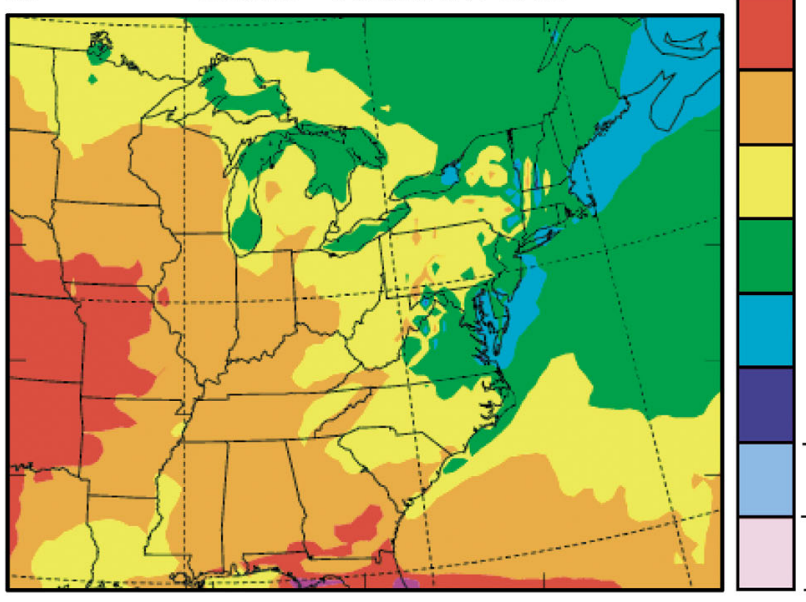

Incident Surface Radiation $\left(\mathrm{W} \mathrm{m}^{-2}\right)$

Fig. 4. Differences in simulated energy fluxes at the surface, MIBR minus MIGR, for JJA 1993-1997: (A) incident shortwave radiation; (B) downward longwave radiation; (C) shortwave + longwave radiative fluxes 
more important role in the west, while daytime radiation and boundary layer processes played a more important role in the east, especially the southeast.

Fig. 7 compares the peak time of precipitation for the modified Grell, the original Grell, and the Betts-Miller scheme. The peak time of precipitation was determined usually by the peak time of convective precipitation. Fig. 7 shows that the inclusion of the radiation and boundary layer processes in the modified Grell are necessary to capture the complexity in the diurnal cycle of observed precipitation shown in Fig. 6. Interestingly, the original Grell results (Fig. 7C), which depend on advective processes for triggering of convection, were more similar to Betts-Miller (Fig. 7B) than to the modified Grell (Fig. 7A). This makes sense since the Betts-Miller scheme depends on the cloudiness, which is quite sensitive to advective process.

Fig. 7 explains, in part, why Betts-Miller surface temperatures were warmer than Grell. Note that the BettsMiller generated rain mostly at night, rather than in the daytime as observed (and as in the modified Grell simulations). Hence, the nighttime temperatures were warmer with Betts-Miller, while a lack of precipitation during the day lead to greater absorption of solar radiation at the surface than in Grell (Fig. 4) and con- sequently excessive surface temperatures. The contrasting timing of significant precipitation episodes in Betts-Miller and Grell explains, in part, an apparent paradox in the model results. The Betts-Miller simulated more rain than Grell overall, but was warmer, because the rain occurred mostly at night.

Yet, the representation of the diurnal cycle can be quite reasonable while the mean temperature field still exhibits large differences between modeled values and observations (see Fig. 2). To address this issue, the simulation for JJA 1993 was repeated with the KainFritsch scheme, which, like the modified Grell used here, also has a triggering function that is clearly sensitive to the daytime boundary layer forcing. Results (not shown) featured a spatial distribution of the timing of peak rainfall that resembled the modified Grell shown in Fig. 7. Nevertheless, at least for 1993, the simulated surface temperatures (not shown) were considerably warmer than those with the modified Grell. This is due to a greater partitioning of convective versus non-convective precipitation, which allows for more surface solar heating. In fact, the Betts-Miller had the largest convective amount of rain, and it produced much warmer temperatures than the Grell in 1993 (not shown).
Fig. 5. JJA precipitation totals averaged over 1993-1997. (A) observations (courtesy of Climate Research Unit, East Anglia University; New et al. 2000; (B) MIBR; (C) MIGR; (D) MIGR modified (see text)

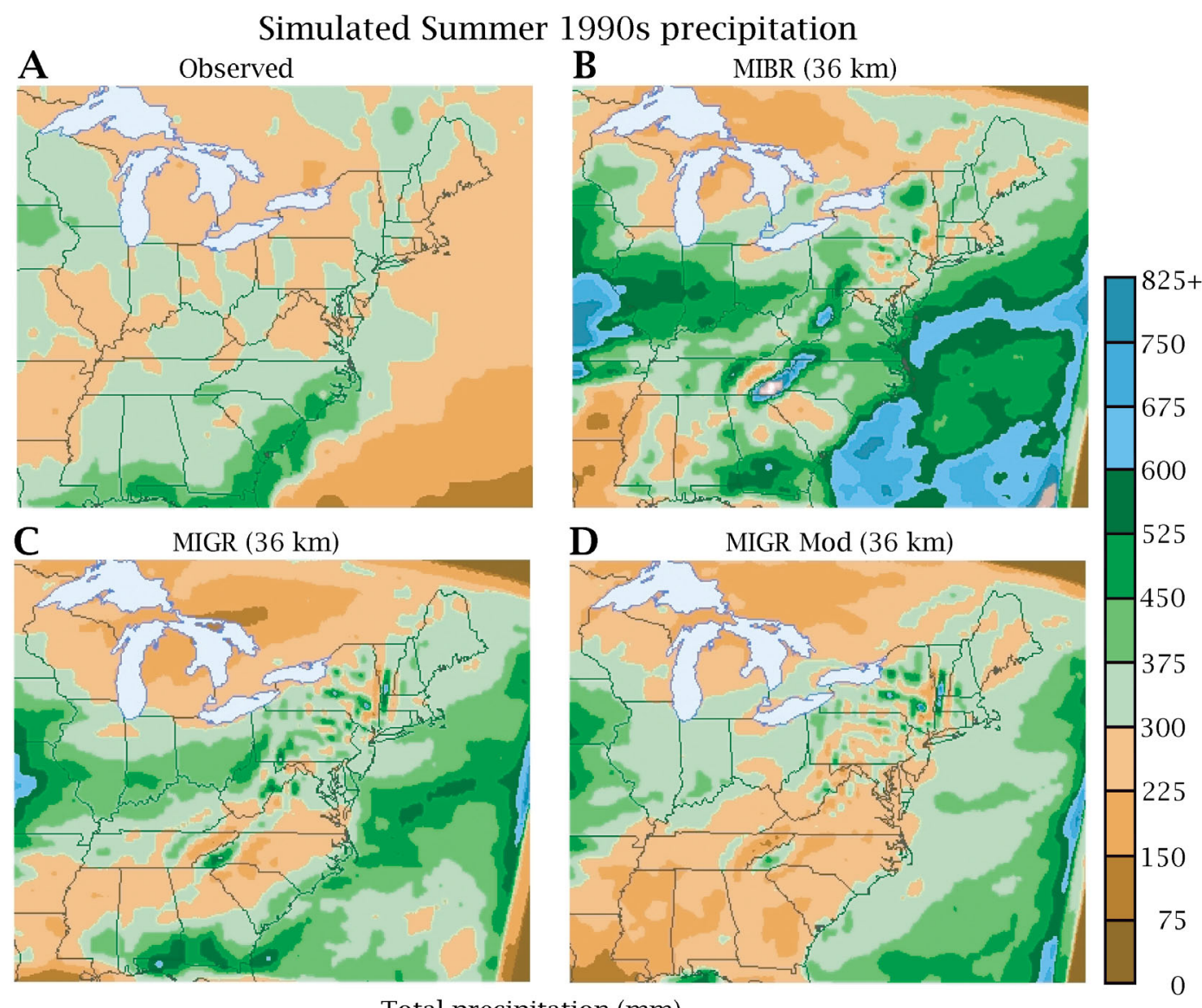

Total precipitation (mm) 
A variety of approaches for modeling cloud microphysics in the MM5 are available. For example, different bulk parameterizations are used for warm rain, simple ice, and mixed phase microphysics. One of the most advanced microphysics scheme is 'Reisner2' (Reisner et al. 1998). The Reisner2 scheme predicts cloud, rain water, snow, graupel, ice, and ice number concentration, and it can also produce super-cooled rain. The Reisner2 scheme was used in all but one of the simulations described below. An alternative scheme, the 'Simple-Ice' scheme was used in a single seasonal simulation (JJA 1993) with the Grell cumulus parameterization. 'Simple-Ice' simulates cloud water and rain when temperatures are above freezing, and it assumes either cloud ice or snow for sub-freezing temperatures (Dudhia 1989). The scheme does not produce super-cooled water, graupel or hail, and all ice/snow melts when temperatures are above freezing.

Given the possible importance of resolved precipitation on surface temperatures, we considered that excessively cool temperatures in the Grell simulations could be related to the use of the Reisner2 scheme. To test this, a single simulation was made for the summer of 1993 using the Simple-Ice scheme, and it did result in warmer temperatures than Grell with Reisner2. The positive impact on surface air temperatures $\left(1\right.$ to $\left.2{ }^{\circ} \mathrm{C}\right)$ was especially pronounced in the Middle West where the simulation with Reisner2 was cooler than observed.

Results for JJA 1993 show that the Simple-Ice simulation and the Reisner2 simulation had very similar amounts of cloud hydrometeor mass in the lower troposphere. However, the Reisner2 produced much more cloud hydrometeor mass (especially cloud water and super-cooled water) in the middle troposphere than did the Simple-Ice scheme. These clouds were apparently more effective in blocking solar radiation than clouds generated by the Simple-Ice scheme, which had more cloud ice hydrometeor mass than Reisner2 in the upper troposphere. This analysis suggests that the choice of non-convective explicit scheme affects simulated seasonal, temperatures-especially when combined with a convective scheme that allows significant non-convective precipitation (i.e. Grell) - even when the timing of the precipitation is realistic.

\section{ALTERNATIVE CLIMATE SCENARIOS FOR THE 2050s AND 2080s}

Fig. 8 shows the Betts-Miller and Grell simulated domain-wide average surface temperatures in the 1990s, 2050s, and 2080s and the observed average for 1993-1997. The Reisner2 scheme was used in all simulations (how the choice of the non-convective scheme might impact simulated climate change is not consid-

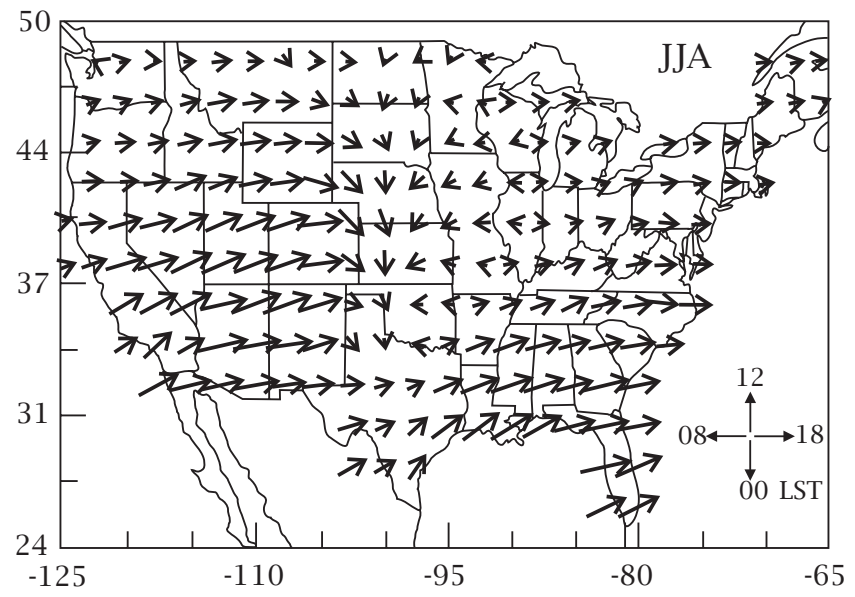

Fig. 6. A representation of the diurnal cycle of precipitation (from Dai et al. 1999). The orientation of the arrows indicates the most frequent local time of rainfall. Refer to key at lower right corner. LST = local standard time. The length of each arrow represents the relative frequency of each peak

ered). The Betts-Miller simulated warmer temperatures than Grell in each decade, and the differences between them grew between the 2050s and the 2080s from about $2^{\circ} \mathrm{C}$ to almost $3.5^{\circ} \mathrm{C}$ (see also Table 1). Fig. 9 shows the Cumulative Distribution Function of domain-wide daily maximum temperatures for BettsMiller and Grell. The interannual variability, as forced by the GISS-GCM, becomes larger from decade to decade, and the Betts-Miller simulated temperatures vary more than the corresponding Grell values. To illustrate this point, Table 2 shows an index of interannual variability - namely, the variance of the annual domain-wide median daily maximum temperature over the 5 summers simulated for each decade-for each of the model simulations listed in Table 1. It can be seen that all model configurations under-estimated interannual variability for the 1990s, the Grell-configurations more so than the Betts-Miller configuration. Interannual variability remained fairly constant from the 1990s to the 2050s, but shows a large increase for the 2080s. As evident from Fig. 9, this is mainly due to the anomalously hot summer of 2086 and cool 2084.

Table 2. Variance $\left({ }^{\circ} \mathrm{C}^{2}\right)$ of the 5 annual domain-wide median values of the daily maximum temperature simulated by the different models for the decades of the 1990s, 2050s and 2080s

\begin{tabular}{|lccc|}
\hline Data set & $1990 \mathrm{~s}$ & $2050 \mathrm{~s}$ & $2080 \mathrm{~s}$ \\
\hline Observed & 0.61 & & \\
MIBR MM5 & 0.44 & 0.27 & 10.88 \\
MIGR Mod & 0.16 & 0.09 & 3.01 \\
MIGR Orig & 0.06 & 0.04 & 4.84 \\
\hline
\end{tabular}



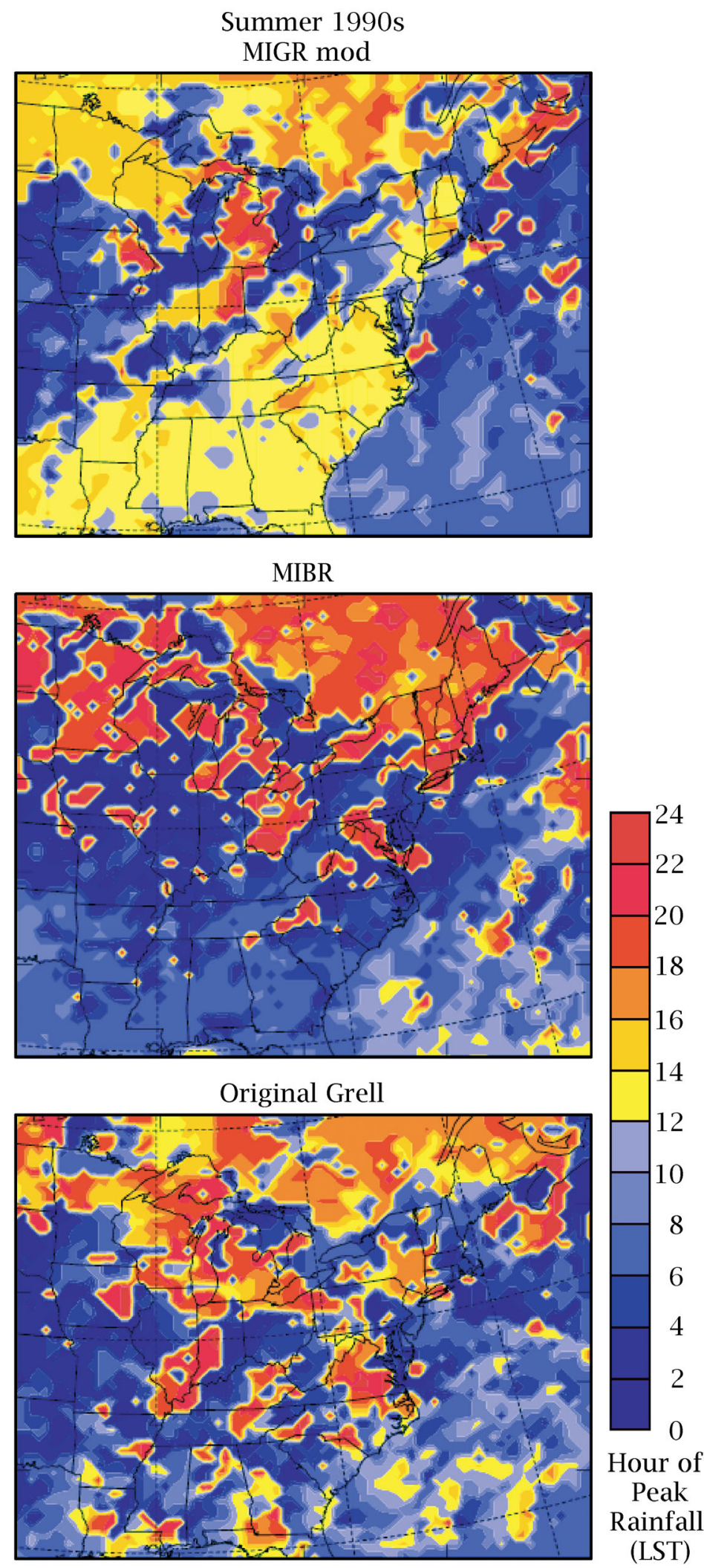

Fig. 7. Spatial distributions of the hour of peak rainfall for each of 3versions of the GISS-MM5: (A) MIGR for JJA 1993-1997: (B) MIBR for JJA 1993-1997; (C) original Grell for JJA 1993-1997
No physical explanation for such large variability of surface temperatures during the 2080s comes to mind.

Fig. 10 shows the time of peak rainfall for BettsMiller and Grell in the 2080s. The time of peak precipitation in Betts-Miller has become generally earlier than in the 1990s, while in Grell, the peak time has become generally later (except in the western part of the domain where the timing is more similar to BettsMiller). The shift to more nighttime convection suggests that advective processes are becoming more 'forceful' in triggering or causing moist convection, while the shift to more afternoon convection implies additional activity triggered by radiation and boundary layer processes.

Fig. 11 shows the domain-wide average convective and non-convective precipitation for Betts-Miller and Grell for each hour of the diurnal cycle during each decade. The Betts-Miller convective precipitation increases considerably at all hours of the day from decade to decade, while the non-convective precipitation generally decreased during the day, although the change was not as clear as above. For the Grell results, there is a smaller increase in convective precipitation between the 1990s and 2080s than for the Betts-Miller scheme, and there is a small increase in non-convective precipitation as well. Fig. 11 shows that the largest precipitation increases between the 1990s and the 2080s for the Betts-Miller scheme were overnight while the largest corresponding increases for the Grell scheme were during the afternoon hours.

These differences in precipitation amount and timing have a very important effect on the radiation fluxes at the surface. Fig. 12 shows the shortwave and long-

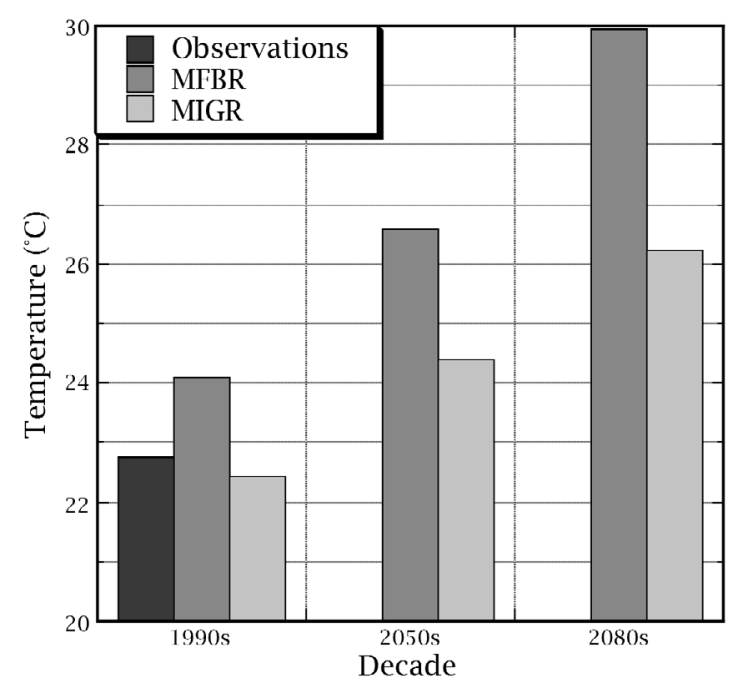

Fig. 8. Domain-averaged surface temperatures for observations, MIBR and MIGR simulations. The 1990s = JJA $1993-1997$; the 2050s $=2053-2057$; the 2080 s $=2083-2087$ 

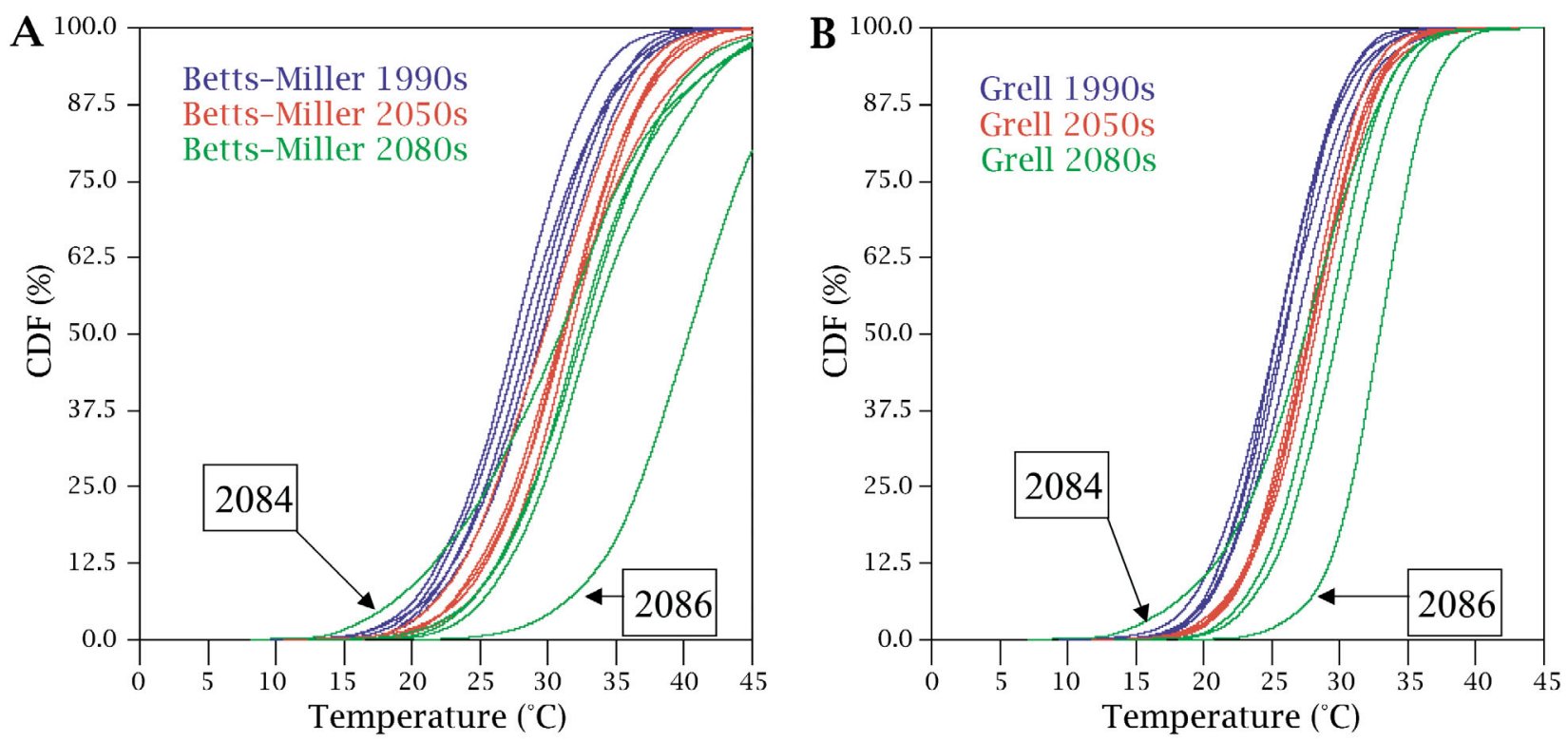

Fig. 9. Domain averaged cumulative density function (CDF) of daily temperatures for each simulated JJA season for (A) MIBR and (B) MIGR

wave radiation fluxes incident at the surface. The magnitude of the shortwave radiation reaching the surface for the Betts-Miller scheme increases from the 1990s to the 2050s, and then from the 2050s to 2080s, presumably as a consequence of less afternoon cloudiness. In comparison, for the Grell results there was relatively no change in the amount of shortwave radiation from decade to decade. Note that the net downward long- wave radiation in both Betts-Miller and Grell increases decadally, a consequence of higher atmospheric temperatures that are driven by the higher surface temperatures. But, these increases are greater with the BettsMiller scheme, which leads to greater differential heating of the land surface and the overlying atmosphere than does the Grell scheme, causing enhanced decadal warming in that scenario.

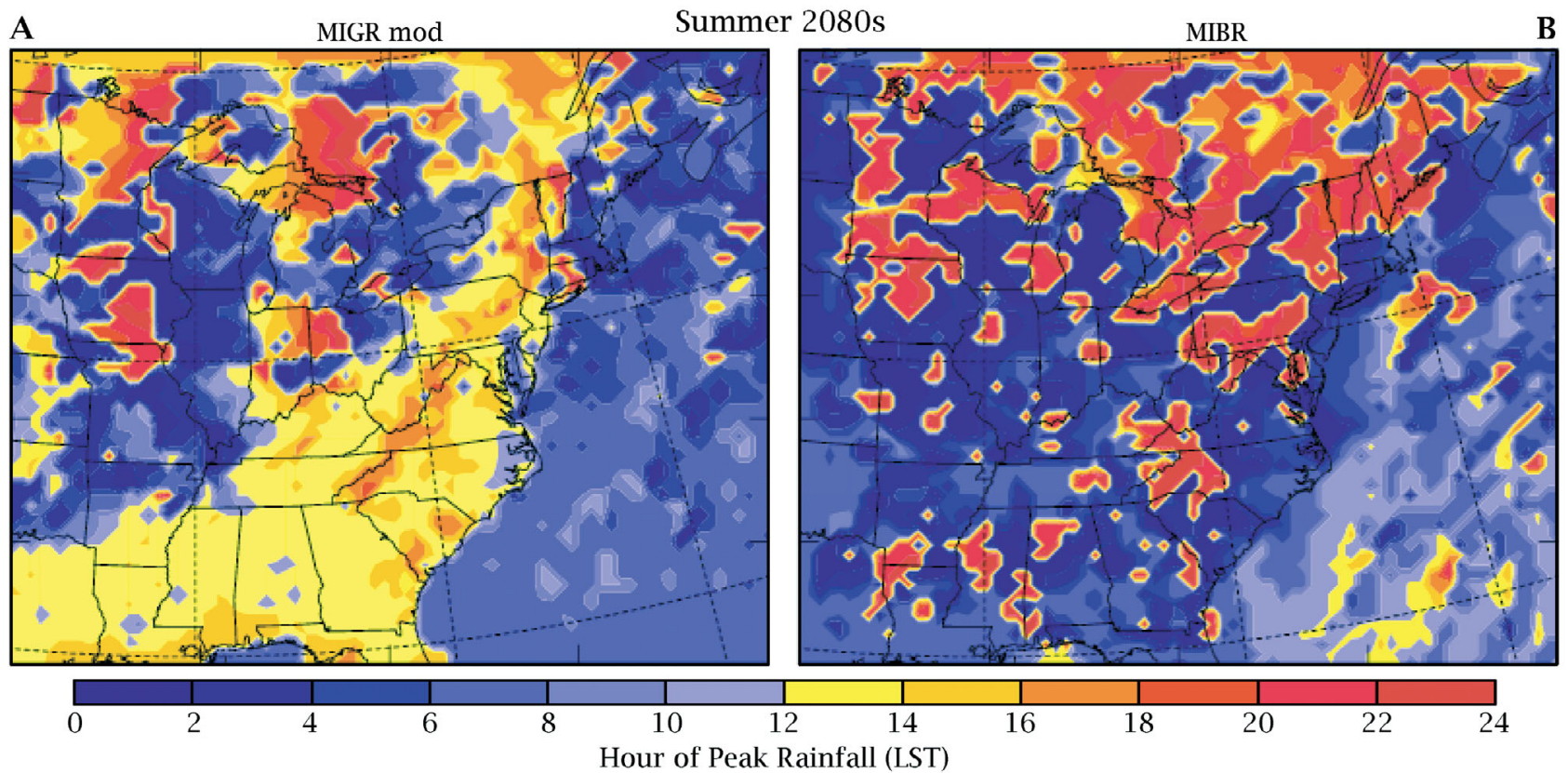

Fig. 10. Spatial distributions of the hour of peak rainfall for each of 3 versions of the GISS-MM5. (A) MIGR for JJA 2083-2087; (B) MIBR for JJA 2083-2087 

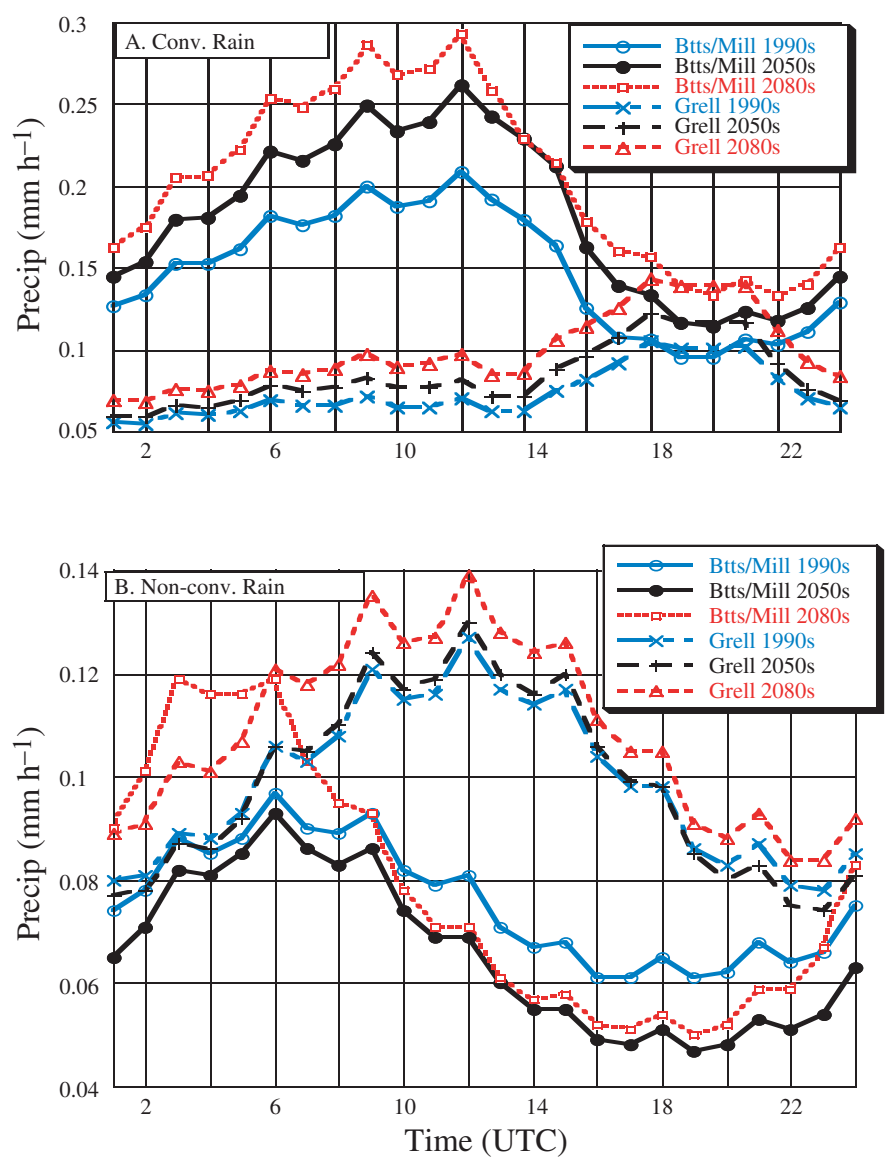

Fig. 11. Domain averaged precipitation rates for each hour of the diurnal cycle for the MIBR (Btts/Mill) and MIGR (Grell) simulations during JJA of each decade. (A) Convective rainfall; (B) non-convective rainfall. UTC: Universal Time (Coordinated)

\section{DISCUSSION AND CONCLUSIONS}

The diurnal cycle of precipitation is quite different from region to region over the United States. Yet, many models, especially global climate models, fail to accurately simulate the timing of precipitation (Trenberth et al. 2003). The current efforts were intended to improve the spatial and temporal representation of climate change characteristics, of which precipitation is a very important component. To this end, a mesoscale model, the MM5, was double-nested on outer and inner grids with 108 and $36 \mathrm{~km}$ spacing, respectively, in a General Circulation Model, the GISS-GCM. Five summers of simulations were made during each of 3 decades, and the average climate statistics for the 1990s, 2050s, and 2080s were analyzed. Results showed that the MM5 simulated the spatial variability of the diurnal cycle over the eastern half of the US better with one convection scheme than with a second, alternative parameterization. MacCracken et al. (2003)
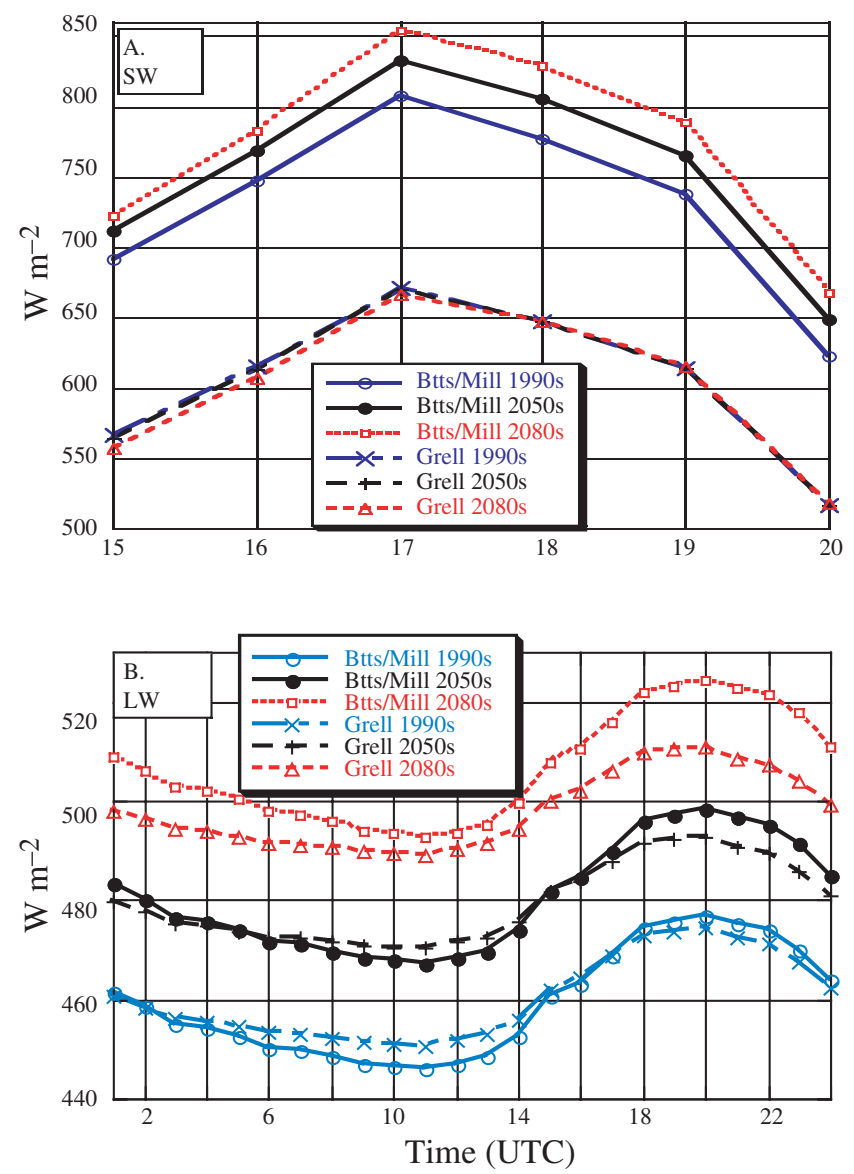

Fig. 12. Domain averaged radiative flux at the surface for the designated hours of the diurnal cycle for the MIBR (Btts/Mill) and MIGR (Grell) simulations during JJA of each decade. (A) Incident short-wave; (B) downward longwave. UTC: Universal Time (Coordinated)

recently pointed out that different model representations of physical processes create different sensitivities to changes in greenhouse gas concentrations. Indeed, further evaluation of these experiments strongly implies that the timing of precipitation, which depended on the choice of convection scheme, has very important consequences for the simulation of surface temperatures in hindcasts and in projections of climate change.

The first set of experiments used a modified Grell cumulus scheme, which included the effect of radiative and boundary forcing on the triggering of moist convection. These runs simulated the diurnal cycle quite well, producing the peak precipitation at approximately the correct time of day from region to region. Interestingly, simulated decadal changes in precipitation (with this version) mitigated the warming trend of surface temperatures. Simulations in the 2080s produced more convective precipitation during the afternoon, as well as more non-convective precipitation, causing a moderation in surface warming, and accord- 
ingly, more moderate temperature extremes, as compared to the set of simulations described below.

The second suite of experiments used the BettsMiller cumulus convection scheme. The Betts-Miller scheme, it turns out, is ideally suited for simulating moist convection where large-scale convergence dominates local boundary layer forcings, or over warm ocean water where changes in atmospheric stability can lead to early morning convection. In the current MM5 simulations, the Betts-Miller version produced a maximum in convective precipitation during the early morning over almost the whole (eastern US) simulation domain. The relatively lower rates of precipitation during the daytime led to greater shortwave heating of the land surface and higher surface air temperatures. This effect was amplified by a decadal decrease in afternoon precipitation, probably owing to greater stabilization associated with increased convective precipitation at night. Hence, surface temperatures increased considerably from the 1990 s to the 2080 s, reaching values comparable to some of the warmest climate prediction models. In addition, when surface temperatures were higher, so too were atmospheric temperatures, causing elevated fluxes of downward longwave energy that reinforced the warming trends.

Modeled convective downdrafts, as in the Grell formulation (but not accounted for by this version of the Betts-Miller scheme) undoubtedly stabilize the atmosphere and have a limiting influence on convective rainfall rates. Moreover, the utilization of the Grell moist convection triggering function proved necessary to activate afternoon showers by local surface forcing. Lacking this triggering mechanism and downdrafts to stabilize the atmosphere, the Betts-Miller version allowed less stable atmospheres to survive until the moisture could be released by nocturnal or early morning instabilities.

A comparison of results between the modified Grell and the 'original' Grell implied that it is preferable to include daytime radiation and boundary layer forcings in triggering functions in order to simulate better the diurnal cycle of precipitation. Further support for this argument is implied by results from the Kain-Fritsch cumulus convection scheme, which also includes a triggering function (although differences here about the time-scale of convection might also to be important in the partitioning between convective versus nonconvective precipitation).

The routine emphasis to get modeled precipitation amounts correct has somewhat neglected the need to correctly partition between convective and nonconvective or to model a realistic diurnal cycle. Yet, recent investigations suggest that precipitation type does influence other atmospheric properties, and it varies significantly within the diurnal cycle, seasonally and from region to region (Dai et al. 1999, Gutowski et al. 2003, Nesbitt \& Zipser 2003). The partitioning between convective and non-convective precipitation and the diurnal cycle matter, not only because rates and timing determine the split between runoff and absorption by the soil, but also because these characteristics have an impact on the simulation of long term surface temperature trends. An additional, subtler sensitivity of modeled surface temperature relates to the simulated phase type of non-convective cloud hydrometeors. In a test with an alternative scheme over a single summer for which simulated clouds were less opaque to shortwave insolation, seasonal mean surface temperatures were higher than in the control experiment.

The important lesson here is that trends of global warming are clearly sensitive to the diurnal cycle of precipitation. Changes in that cycle will alter daytime heating rates and future temperature maximums, with nocturnal precipitation peaks favoring higher temperatures. The differences in the 2 scenarios are large enough to significantly alter contingency plans in such sectors as public health and energy. An additional lesson is that model simulations of climate change will not provide realistic temperature projections unless they correctly simulate the spatial variability of the diurnal cycle of precipitation. Improvements in modeling moist convection should advantageously limit the range of solutions from alternative schemes. More importantly, as improvements are realized, they will contribute to a greater confidence in projections of climate change.

Acknowledgements. This work was supported by the NASA Climate Program and the U.S. Environmental Protection Agency's National Center for Environmental Research (NCER) STAR Program, under Grant R-828733. B.H.L. received additional support under EPA Grant R-83096. L.D. was partially supported by NSF Grants ATM-0089563 and ATM-0354589. The authors thank Drs. George Grell and Alan Betts for their suggestions, and José Mendoza for re-drafting Fig. 6

Disclaimer. Although the research described in this article has been funded in part by the U.S. Environmental Protection Agency, it has not been subjected to the Agency's required peer and policy review and therefore does not necessarily reflect the views of the Agency and no official endorsement should be inferred.

\section{LITERATURE CITED}

Anthes RA, Kuo YH, Hsie EY, Low-Nam S, Bettge TW (1989) Estimation of skill and uncertainty in regional numerical models. Q J R Meteorol Soc 115:763-806

Bates, GT, Giorgi F, Hostetler SW (1993) Towards the simulation of the effects of the Great Lakes on regional climate. Mon Wea Rev 121:1373-1387

Betts AK (1986) A new convective adjustment scheme, Part I: Observational and theoretical basis'. Q J R Meteorol Soc 112:677-692 
Betts AK, Miller MJ (1986) A new convective adjustment scheme. Part II: Single column tests using GATE wave, Bomex, ATEX and Arctic air-mass data sets. Q J R Meteorol Soc 112:693-709

Betts AK, Miller MJ (1993) The Betts-Miller scheme. In: Emanuel KA, Raymond DJ (eds) The representation of cumulus convection in numerical models of the atmosphere. Am Meteorol Soc Meteor Monogr 24, No. 46: 107-121

Chen F, Dudhia J (2001a) Coupling an advanced landsurface/hydrology model with the Penn State/NCAR MM5 modeling system. Part I: Model implementation and sensitivity. Mon Wea Rev 129:569-585

Chen F, Dudhia J (2001b) Coupling an advanced landsurface/hydrology model with the Penn State/NCAR MM5 modeling system. Part II: Preliminary Model validation. Mon Wea Rev 129:587-604

Dai A (1999) Recent changes in the diurnal cycle of precipitation over the United States. Geophys Res Lett 26:341-344

Dai A, Giorgi F, Trenberth K (1999) Observed and model simulated precipitation diurnal cycles over the contiguous United States. J Geophys Res 104:6377-6402

Dudhia J (1989) Numerical study of convection observed during winter monsoon experiment using a mesoscale 2 dimensional model. J Atmos Sci 46:3077-3107

Dudhia J (1993) A nonhydrostatic version of the Penn State/ NCAR mesoscale model: Validation tests and simulation of an Atlantic cyclone and cold front. Mon Wea Rev 121:1493-1513

Giorgi F, Bates G and Nieman S (1993) The Multiyear Surface Climatology of a Regional Atmospheric Model over the Western United States. J Climate 6:75-95

Grell G (1993) Prognostic evaluation of assumptions used by cumulus parameterizations. Mon Wea Rev 121:764-787

Grell G, Kuo YH, Pasch RJ (1991) Semi-prognostic tests of cumulus parameterization schemes in the middle latitudes. Mon Wea Rev 119:5-31

Grell GA, Dudhia J, Stauffer DR (1994) A description of the fifth-generation Penn State/NCAR mesoscale model (MM5). NCAR Technical Note, NCAR/TN-398+STR, National Center for Atmospheric Research (NCAR), Boulder, CO

Gutowski W, Decker S, Donavon R, Pan Z, Arritt R, Takle E (2003) Temporal-spatial scales of observed and simulated precipitation in Central U.S. climate. J Climate 16: 3841-3847

Hogrefe C, Rao ST, Kasibhatla P, Kallos G and 6 others (2001) Evaluating the performance of regional-scale photochem-

Editorial responsibility: Otto Kinne, Oldendorf/Luhe, Germany ical modeling systems: Part I-meteorological predictions. Atmos Environ 35:4159-4174

Hogrefe C, Biswas J, Lynn B, Civerolo K and 5 others (2004) Simulating regional-scale ozone climatology over the Eastern United States: Model evaluation results. Atmos Environ 38:2627-2638

Janjic Z (1994) The step-mountain ETA coordinate model: Further development of the convection, viscous sublayer, and turbulent closure schemes. Mon Wea Rev 122:927-945

Kain JS, Fritsch JM (1993) Convective parameterization for mesoscale models: The Kain-Fritsch scheme. In: Emanuel KA and Raymond DJ (eds) The representation of cumulus convection in numerical models of the atmosphere. Am Meteorol Soc Meteor Monogr 24, No. 46

Kunkel K, Andsager K, Liang XZ, Arritt R, Takle E, Gutowski W, Pan Z (2002) Observations and regional climate model simulations of heavy precipitation events and seasonal anomalies: A comparison. J Hydrometeorol 3:322-334

Liang XZ, Kunkel K, Samel A (2001) Development of a regional climate model for U.S. Midwest Applications. Part I: Sensitivity to buffer zone treatment. J Climate 14: 4363-4378

MacCracken M, Barron E, Easterling D, Felzer B, Karl T (2003) Climate change scenarios for the US national assessment. Bull Am Meteorol Soc 84:1711-1723

Nesbitt S, Zipser E (2003) The diurnal cycle of rainfall and convective intensity according to 3 years of TRMM measurements. J Climate 16:1456-1475

New M, Hulme M, Jones P (2000) Representing twentiethcentury space-time climate variability. Part II: Development of 1901-96 monthly grids of terrestrial surface climate. J Climate 13:2217-2238

Nobre P, Moura A, Sun L (2001) Dynamical downscaling of seasonal climate prediction over Nordeste Brazil with ECHAM3 and NCEP's regional spectral models at IRI. Bull Am Meteorol Soc 82:2787-2796

Reisner J, Rasmussen J, Bruintjes R (1998) Explicit forecasting of supercooled liquid water in winter storms using the MM5 mesoscale model. Q J R Meteorol Soc 124B:1071-1107

Russell G, Miller J, Rind D (2003) A coupled atmosphereocean model for transient climate change studies. Atmosphere-Ocean 33:683-730

Trenberth K, Dai A, Rasmussen R, Parsons D (2003) The changing character of precipitation. Bull Am Meteorol Soc 84:1205-1217

Walsh K, McGregor J (1995) January and July climate simulations over the Australian region using a limited-area model. J Climate 8:2387-2403

Submitted: March 22, 2004; Accepted: November 15, 2004

Proofs received from author(s): December 7, 2004 
